\title{
Substituting Doxorubicin with Nonpegylated Liposomal Doxorubicin for the Treatment of Early Breast Cancer: Results of a Retrospective Study
}

\author{
Neville Davidson, ${ }^{1,2}$ Teresa Camburn, ${ }^{1}$ Ian Keary, ${ }^{3}$ and David Houghton ${ }^{2}$ \\ ${ }^{1}$ Broomfield Hospital, Court Road, Chelmsford, Essex CM1 7ET, UK \\ ${ }^{2}$ Rivers Hospital, High Wych Road, Sawbridgeworth Hertfordshire CM21 OHH, UK \\ ${ }^{3}$ Strategen Limited, 2 \& 3 Stable Court, Herriard Park Estate, Herriard, Basingstoke RG25 2PL, UK \\ Correspondence should be addressed to Ian Keary; ian.keary@strategen.co.uk
}

Received 1 October 2013; Accepted 10 December 2013; Published 12 January 2014

Academic Editor: Ian S. Fentiman

Copyright ( 2014 Neville Davidson et al. This is an open access article distributed under the Creative Commons Attribution License, which permits unrestricted use, distribution, and reproduction in any medium, provided the original work is properly cited.

\begin{abstract}
Introduction. Evidence from the metastatic setting suggests that replacing conventional doxorubicin with nonpegylated liposomal doxorubicin (NPLD) for early breast cancer may maintain efficacy whilst reducing long-term cardiotoxicity, an important consideration with many patients going on to receive multiple lines of treatment. Methods. Consecutive patients with early breast cancer treated with NPLD were assessed for disease progression and changes in cardiac function according to left ventricular ejection fraction (LVEF). Results. Ninety-seven patients (median age at diagnosis 51 (32-76) years) were studied. The majority received NPLD $\left(60 \mathrm{mg} / \mathrm{m}^{2}\right.$ plus cyclophosphamide $\left.600 \mathrm{mg} / \mathrm{m}^{2}\right)$ adjuvantly $(79.4 \%)$ and in sequence with a taxane $(79.4 \% ;$ docetaxel $\left.75 \mathrm{mg} / \mathrm{m}^{2}\right) .80 .4 \%$ had radiotherapy and $15.5 \%$ received trastuzumab. Mean time to disease recurrence was 87.0 months $(80.7-93.2$ [95\% confidence interval]) and 5-year disease-free survival was $86.0 \%$. Mean LVEF values remained within the normal range of $\geq 55 \%$ during treatment and throughout the cardiac follow-up period (median 7 months, range 1-21 months). Use of trastuzumab and age at diagnosis did not appear to influence LVEF. Conclusion. NPLD appeared to be a well-tolerated substitute for conventional doxorubicin in patients with early breast cancer.
\end{abstract}

\section{Introduction}

Nonpegylated liposomal doxorubicin (NPLD; Myocet, Teva UK) has potential advantages over conventional doxorubicin in the treatment of early breast cancer. Utilising a less cardiotoxic but equally effective treatment earlier in management may help to maximise therapeutic options later in the course of disease and thereby facilitate the use of multiple lines of therapy. In addition, substituting NPLD for doxorubicin as the standard anthracycline in early breast cancer may help address the growing concerns regarding the longer-term impact of treatment on cardiac function, a key survivorship issue $[1,2]$. However, whilst NPLD has been extensively studied in metastatic breast cancer and is licensed in this regard [3-7], data on its use in early disease are currently scarce $[8,9]$.
As advances in diagnosis, management, and treatment have led to improved breast cancer survival, the issue of longer-term, therapy-related cardiotoxicity has taken on increasing importance, with patients potentially facing multiple, coincident insults to the heart [10]. Many of the available adjuvant therapies, which are increasingly used in combination or sequence, have been associated with some form of cardiotoxicity during or after therapy, whilst increasing age, comorbid conditions, and disease-related decreases in physical activity can also contribute to cardiovascular disease [10]. In addition to cumulative cardiotoxicity potentially limiting treatment options and therefore outcomes, acute improvements in breast cancer survival may be offset by increases in cardiovascular disease and mortality $[1,2]$. Therefore, the challenge for the clinician, particularly in the early breast cancer setting, is to balance the need for anticancer efficacy 
against the potential for subsequent treatment-related cardiovascular disease and mortality.

Data from the metastatic setting, which demonstrate that NPLD is equally efficacious but significantly less cardiotoxic than conventional doxorubicin $[3,4,6]$, provide a good rationale to postulate that NPLD may help achieve this delicate balance in the adjuvant setting. The results of two small phase II studies $[8,9]$ suggest that the benefits observed in metastatic patients may be maintained in early breast cancer, but further data are required. The objective of our study, therefore, was to assess the use of NPLD in place of conventional doxorubicin in standard regimens as a novel therapeutic option for the treatment of patients with early breast cancer.

\section{Materials and Methods}

The objective of this study was to assess the efficacy and cardiac tolerability of NPLD as a substitute for conventional doxorubicin in patients with early breast cancer in routine clinical practice. Efficacy was assessed in terms of disease recurrence and survival, whilst cardiac function was assessed according to left ventricular ejection fraction (LVEF).

The medical records of all patients with early breast cancer receiving treatment with NPLD at the Rivers Hospital, Chelmsford, UK, between January 2003 and August 2011 were retrospectively reviewed and the following information was extracted: date of diagnosis, date of surgery, TNM stage, type of surgery, chemotherapy regimen, radiotherapy schedule, use of endocrine therapy, use of trastuzumab, and the dates of LVEFs derived from any echocardiograms. Details of disease recurrence and mortality were also recorded. All data were anonymised. Ethical review and patient consent were deemed unnecessary by the local review board, in line with the National Research Ethics Service (NRES) guidance document, as the study was considered a service evaluation [11].

2.1. Data Analysis. Time to recurrence and 5-year diseasefree survival were estimated for the total study population using Kaplan-Meier analysis. All patients who had the minimum of a baseline (i.e., immediately prior to or during the first cycle of chemotherapy) echocardiogram were included in the analysis of cardiac function. To facilitate analysis, echocardiogram results were grouped according to when they were taken in relation to the timing of chemotherapy. If a patient had more than one reading in a given time period, the lowest LVEF obtained was used. Additional analyses were performed for the following subgroups: primary versus adjuvant therapy, NPLD regimen used, whether patients received adjuvant trastuzumab or not, and patient age ( $\geq 60$ years versus $<60$ years). Patients with LVEF values $\geq 55 \%$ were considered to have normal cardiac function, as defined by current British Society of Echocardiography guidelines [10].

\section{Results}

A total of 97 women (median age at diagnosis 51 [32-76] years) were studied (Table 1). Seventy-seven (79.4\%) patients were treated adjuvantly, with the remainder receiving NPLD
TABLE 1: Baseline demographic characteristics.

\begin{tabular}{|c|c|}
\hline Number of evaluable patients & 97 \\
\hline Median age at diagnosis (range) & $51(32-76)$ \\
\hline \multicolumn{2}{|l|}{ TNM stage $[n(\%)]$} \\
\hline I & $20(20.6 \%)$ \\
\hline II & $41(42.3 \%)$ \\
\hline IIA & $4(4.1 \%)$ \\
\hline IIB & $5(5.2 \%)$ \\
\hline III & $21(21.6 \%)$ \\
\hline IIIA & $5(5.2 \%)$ \\
\hline Unknown & $1(1.0 \%)$ \\
\hline \multicolumn{2}{|l|}{ Type of surgery $[n(\%)]$} \\
\hline Mastectomy & $51(52.6 \%)$ \\
\hline Wide local excision & $46(47.4 \%)$ \\
\hline \multicolumn{2}{|l|}{ Chemotherapy regimen $[n(\%)]$} \\
\hline Primary & $20(20.4 \%)$ \\
\hline Adjuvant & $78(79.6 \%)$ \\
\hline \multicolumn{2}{|l|}{ Anthracycline regimen $[n(\%)]^{*}$} \\
\hline $\mathrm{AC}$ & $4(4.1 \%)$ \\
\hline $\mathrm{AC}+\mathrm{T}$ & $77(79.4 \%)$ \\
\hline TAC & $16(16.5 \%)$ \\
\hline \multicolumn{2}{|l|}{ Trastuzumab $[n(\%)]$} \\
\hline Yes & $15(15.5 \%)$ \\
\hline No & $70(72.2 \%)$ \\
\hline Unknown & $12(12.4 \%)$ \\
\hline \multicolumn{2}{|l|}{ Radiotherapy $[n(\%)]$} \\
\hline Yes & $78(80.4 \%)$ \\
\hline No & $19(19.6 \%)$ \\
\hline \multicolumn{2}{|l|}{ Endocrine therapy } \\
\hline Yes & $72(74.2 \%)$ \\
\hline No & $5(5.2 \%)$ \\
\hline Unknown & $20(20.6 \%)$ \\
\hline \multicolumn{2}{|c|}{$\begin{array}{l}\text { *AC: } 6 \text { cycles of NPLD }\left(60 \mathrm{mg} / \mathrm{m}^{2}\right) \text { and cyclophosphamide }\left(600 \mathrm{mg} / \mathrm{m}^{2}\right) \text {. } \\
\text { AC + T: } 4 \text { cycles of NPLD }\left(60 \mathrm{mg} / \mathrm{m}^{2}\right) \text { and cyclophosphamide }\left(600 \mathrm{mg} / \mathrm{m}^{2}\right. \\
\text { followed by } 4 \text { cycles of docetaxel }\left(75 \mathrm{mg} / \mathrm{m}^{2}\right) \text {. } \\
\text { TAC: six cycles of NPLD }\left(60 \mathrm{mg} / \mathrm{m}^{2}\right) \text { and cyclophosphamide }\left(600 \mathrm{mg} / \mathrm{m}^{2}\right. \\
\text { and docetaxel }\left(75 \mathrm{mg} / \mathrm{m}^{2}\right) .\end{array}$} \\
\hline
\end{tabular}

as primary therapy. NPLD was administered at a dosage of $60 \mathrm{mg} / \mathrm{m}^{2}$ combined with cyclophosphamide $\left(600 \mathrm{mg} / \mathrm{m}^{2}\right)$ for 4 or 6 cycles. The majority (79.4\%) of patients received NPLD in sequence with a taxane (docetaxel $75 \mathrm{mg} / \mathrm{m}^{2}$ ). In total, $15.5 \%$ of patients received trastuzumab and $80.4 \%$ had radiotherapy. The median followup from diagnosis was 48 months (range 9-114 months).

3.1. Disease Recurrence or Progression. Eight of the 97 (8.2\%) patients experienced disease recurrence or progression and 2 (2.1\%) died during the study period. Of the 8 patients who relapsed/progressed, 5 had received AC-T without trastuzumab, 2 had received AC-T with trastuzumab, and 1 had received TAC without trastuzumab. The sites of recurrence included bone, lymph nodes, liver, lung, and the contralateral breast. Kaplan-Meier analysis estimated that the mean time 


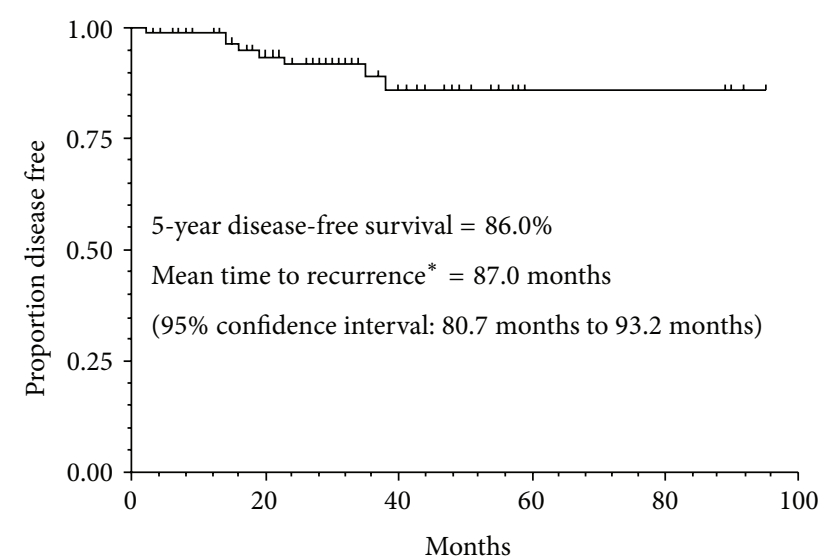

*: Median time to recurrence could not be calculated due to low number of events

FIgURE 1: Kaplan-Meier survival plot for disease-free survival following surgery $(n=97)$.

to recurrence was 87.0 months after surgery and that 5-year disease-free survival was $86.0 \%$ (Figure 1).

3.2. Cardiac Function. Seventy-six patients had at least a baseline echocardiogram and were included in the cardiac function analysis. The median cardiac follow-up period (i.e., time between the baseline and last recorded echocardiogram) was 7 months (range 1-21 months). Mean LVEF values remained within the normal range $(\geq 55 \%)$ and were stable at baseline (64.2\%), during chemotherapy (64.4\%), and at other specified time points over the study period (range: $62.8 \%-$ $65.0 \%$; Figure 2). In total, 9 patients had at least one LVEF in the range $45 \%-54 \%$, which corresponds to a mild depression of LVEF [10]. Of these patients, 4 had baseline LVEFs of $45 \%-54 \%$ that returned to the normal range following chemotherapy, 3 experienced a fall in LVEF to $45 \%-54 \%$ during chemotherapy but returned to normal levels following treatment completion, 1 patient had a fall of 13 points from $65 \%$ at baseline to $52 \%$ during therapy, and 1 patient had a fall of 6 points from $58 \%$ to $52 \%$ during therapy; no further data for either patient were available beyond this time.

Similarly, no differences in mean LVEF values during or after chemotherapy were observed when patients were compared on the basis of timing of NPLD (primary versus adjuvant), NPLD regimen (AC versus TAC. versus $\mathrm{AC}+\mathrm{T}$ ) or patient age ( $<60$ years versus $\geq 60$ years) (Table 2 ).

No differences in the mean LVEF value were apparent at any time point among those who did and did not receive trastuzumab. Mean LVEF remained in the normal range at baseline $(64.3 \%$ versus $64.2 \%$, resp.), during chemotherapy (66.8\% versus $64.2 \%)$ and at other specified time points during the study period (Figure 3 ). Limiting the analysis to those patients who received NPLD and trastuzumab as adjuvant therapy did not change the outcome (data not shown).

\section{Discussion}

The results of our study suggest that NPLD offers an attractive alternative to conventional doxorubicin in the treatment of

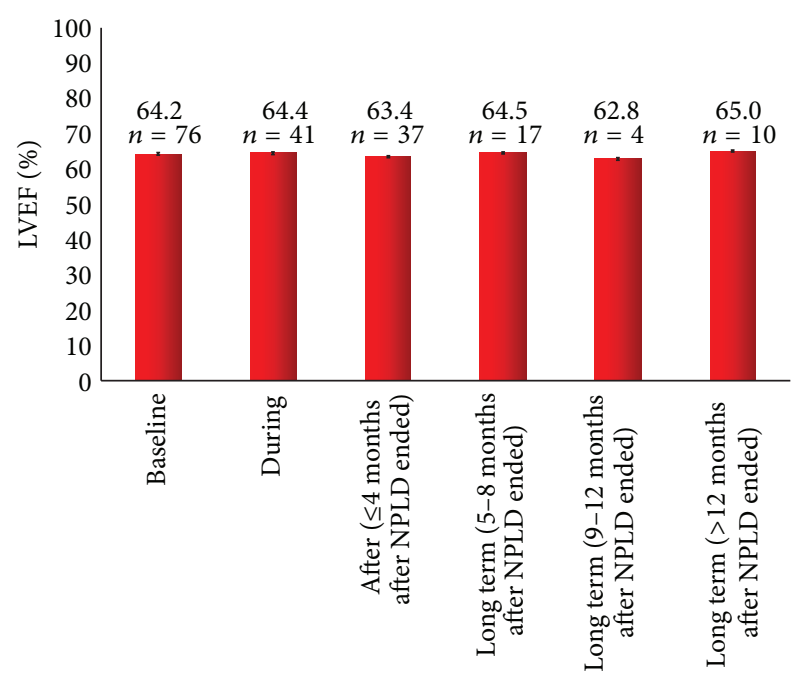

FIgURE 2: Mean ( \pm standard error) LVEF values in the overall patient population.

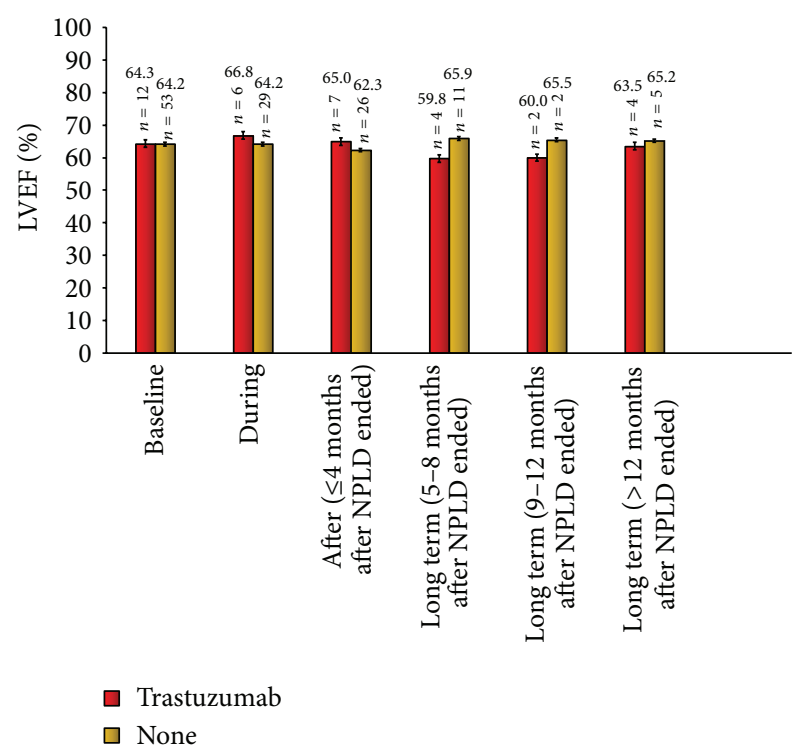

FIGURE 3: Mean ( \pm standard error) LVEF values in patients who did or did not receive trastuzumab.

early breast cancer. When used in standard primary and adjuvant regimens, NLPD appeared to have no detrimental effect on cardiac function. Five-year disease-free survival was $86 \%$; however, interpretation concerning efficacy is constrained by the small size of the study. It is interesting to speculate whether with greater followup, the apparently reduced cardiotoxicity of NPLD would be reflected in improvements in survival through decreased cardiac mortality.

Cardiac function, as assessed by LVEF measurements, remained clinically stable throughout the follow-up period regardless of NPLD timing or regimen, patient age, or trastuzumab use. Indeed, mean LVEF values did not fall below the British Society of Echocardiography [10] definition of a normal LVEF of $55 \%$ in any of the analyses carried out. 
TABLE 2: Mean ( \pm standard error) LVEF (\%) values according to timing of NPLD, regimen used, and age at diagnosis.

\begin{tabular}{|c|c|c|c|c|c|c|c|}
\hline & & Baseline & During & $\begin{array}{c}\leq 4 \text { months after } \\
\text { chemotherapy } \\
\text { ended }\end{array}$ & $\begin{array}{c}\text { 5-8 months } \\
\text { after } \\
\text { chemotherapy } \\
\text { ended }\end{array}$ & $\begin{array}{l}\text { 9-12 months } \\
\text { after } \\
\text { chemotherapy } \\
\text { ended }\end{array}$ & $\begin{array}{c}>12 \text { months after } \\
\text { chemotherapy } \\
\text { ended }\end{array}$ \\
\hline \multirow{2}{*}{$\begin{array}{l}\text { NPLD } \\
\text { timing }\end{array}$} & Adjuvant & $\begin{array}{c}63.9 \pm 0.7 \\
(n=60)\end{array}$ & $\begin{array}{c}64.8 \pm 0.8 \\
(n=33)\end{array}$ & $\begin{array}{c}63.4 \pm 1.3 \\
(n=31)\end{array}$ & $\begin{array}{c}64.8 \pm 1.7 \\
(n=11)\end{array}$ & $\begin{array}{c}62.8 \pm 1.6 \\
(n=4)\end{array}$ & $\begin{array}{c}64.1 \pm 1.6 \\
(n=8)\end{array}$ \\
\hline & Primary & $\begin{array}{c}65.1 \pm 1.3 \\
(n=17)\end{array}$ & $\begin{array}{c}63.0 \pm 1.6 \\
(n=8)\end{array}$ & $\begin{array}{c}63.3 \pm 1.5 \\
(n=6)\end{array}$ & $\begin{array}{c}63.8 \pm 2.8 \\
(n=6)\end{array}$ & No data & $\begin{array}{c}68.5 \pm 1.5 \\
(n=2)\end{array}$ \\
\hline \multirow{3}{*}{$\begin{array}{l}\text { NPLD } \\
\text { regimen }\end{array}$} & $\mathrm{AC}+\mathrm{T}$ & $\begin{array}{c}63.8 \pm 0.7 \\
(n=59)\end{array}$ & $\begin{array}{c}63.9 \pm 0.8 \\
(n=27)\end{array}$ & $\begin{array}{c}63.3 \pm 1.3 \\
(n=29)\end{array}$ & $\begin{array}{c}64.7 \pm 1.5 \\
(n=12)\end{array}$ & $\begin{array}{c}63.7 \pm 1.9 \\
(n=3)\end{array}$ & $\begin{array}{c}64.6 \pm 1.7 \\
(n=7)\end{array}$ \\
\hline & TAC & $\begin{array}{c}66.1 \pm 1.5 \\
(n=14)\end{array}$ & $\begin{array}{c}65.4 \pm 1.7 \\
(n=12)\end{array}$ & $\begin{array}{c}63.9 \pm 2.0 \\
(n=7)\end{array}$ & $\begin{array}{c}64.0 \pm 3.6 \\
(n=5)\end{array}$ & $\begin{array}{c}60.0 \\
(n=1)\end{array}$ & $\begin{array}{c}66.0 \pm 3.1 \\
(n=3)\end{array}$ \\
\hline & $\mathrm{AC}$ & $\begin{array}{c}62.7 \pm 2.7 \\
(n=3)\end{array}$ & $\begin{array}{c}66.0 \pm 2.0 \\
(n=2)\end{array}$ & $\begin{array}{c}60.0 \\
(n=1)\end{array}$ & No data & No data & No data \\
\hline \multirow{2}{*}{$\begin{array}{l}\text { Age at } \\
\text { diagnosis }\end{array}$} & $<60$ & $\begin{array}{c}64.0 \pm 0.8 \\
(n=53)\end{array}$ & $\begin{array}{c}65.1 \pm 0.8 \\
(n=29)\end{array}$ & $\begin{array}{c}62.9 \pm 1.5 \\
(n=25)\end{array}$ & $\begin{array}{c}64.0 \pm 1.6 \\
(n=15)\end{array}$ & $\begin{array}{c}62.8 \pm 1.6 \\
(n=4)\end{array}$ & $\begin{array}{c}64.9 \pm 1.6 \\
(n=8)\end{array}$ \\
\hline & $\geq 60$ & $\begin{array}{c}64.5 \pm 1.0 \\
(n=23)\end{array}$ & $\begin{array}{c}62.8 \pm 1.6 \\
(n=12) \\
\end{array}$ & $\begin{array}{c}64.3 \pm 1.4 \\
(n=12)\end{array}$ & $\begin{array}{c}68.0 \pm 2.0 \\
(n=2)\end{array}$ & No data & $\begin{array}{c}64.5 \pm 2.5 \\
(n=2)\end{array}$ \\
\hline
\end{tabular}

AC: 6 cycles of NPLD $\left(60 \mathrm{mg} / \mathrm{m}^{2}\right)$ and cyclophosphamide $\left(600 \mathrm{mg} / \mathrm{m}^{2}\right)$.

AC + T: 4 cycles of NPLD $\left(60 \mathrm{mg} / \mathrm{m}^{2}\right)$ and cyclophosphamide $\left(600 \mathrm{mg} / \mathrm{m}^{2}\right)$ followed by 4 cycles of docetaxel $\left(75 \mathrm{mg} / \mathrm{m}^{2}\right)$.

TAC: six cycles of NPLD $\left(60 \mathrm{mg} / \mathrm{m}^{2}\right)$ and cyclophosphamide $\left(600 \mathrm{mg} / \mathrm{m}^{2}\right)$ and docetaxel $\left(75 \mathrm{mg} / \mathrm{m}^{2}\right)$.

Individually, 9 patients had LVEFs of $45 \%-55 \%$ recorded; however, this appeared to be reversible, and, to date, none of the patients included in this study have represented with cardiac-related problems.

Our finding that the mean LVEF remained comparable in patients who did and did not receive trastuzumab may have important implications for future treatment strategies. It is well-documented that the use of trastuzumab in combination with anthracyclines has potent antitumour potential but at the cost of prohibitively increased cardiotoxicity $[12,13]$. Our results suggest that use of NPLD should be further investigated both as an alternative to conventional anthracyclines, to maximise subsequent therapy options and thereby as a means of minimising cardiotoxicity-related interruption of trastuzumab therapy, and also as a combined regimen with trastuzumab. Indeed, use of these two agents in combination is already an area of increasing interest [14-16], with preliminary results to date suggesting that it might be a favourable therapeutic approach $[15,16]$.

We recognise that our study is limited by its single centre, retrospective design, lack of an appropriate comparator group, and limited follow-up period in terms of the number of patients with recorded LVEF measurements following the completion of chemotherapy. However, the consistency of our results is encouraging, and we believe that they demonstrate that NPLD may offer a basis for novel treatment regimens for early breast cancer with improved therapeutic indices compared to current standards of care. Further data are required to confirm these promising findings, particularly in the longer term.

\section{Conclusions}

Nonpegylated liposomal doxorubicin (NPLD; Myocet) has been shown to improve the therapeutic index of conventional doxorubicin by significantly reducing the risk of cardiotoxicity when used as first-line therapy for metastatic breast cancer $[3,4,15,16]$. Utilising a less cardiotoxic but equally effective treatment earlier in the management of breast cancer may help to maximise therapeutic options later in the course of disease and thereby facilitate the use of multiple lines of therapy. In addition, substituting NPLD for conventional doxorubicin as the standard anthracycline in early breast cancer (EBC) may help address the growing concerns regarding the longer-term impact of treatment on cardiac function $[1,2]$. Current evidence on the use of NPLD in early disease is restricted to two phase II trials $[8,9]$, both of which report limited cardiac data for NPLD.

In our study, NPLD did not have a detrimental effect on cardiac function, which was maintained for $>12$ months after the completion of treatment. Indeed, mean LVEF values did not fall below the British Society of Echocardiography [10] definition of a normal LVEF of 55\% in any of the analyses carried out. Furthermore, the addition of trastuzumab to NPLD regimens did not result in increased cardiotoxicity. These findings suggest that NPLD may offer a basis for novel treatment regimens for EBC with decreased long-term cardiac impact compared to current standards of care.

\section{Abbreviations}

NPLD: Nonpegylated liposomal doxorubicin

LVEF: Left ventricular ejection fraction

TNM: Tumour node metastasis

AC: Anthracycline

AC-T: Sequential anthracycline then taxane

TAC: Combination taxane and anthracycline

EBC: Early Breast Cancer

NRES: National Research Ethics Service. 


\section{Conflict of Interests}

Neville Davidson and David Houghton have acted as advisors to Teva (UK) Limited and have received honoraria in this regard. Ian Keary (on behalf of Strategen Limited) has received funding from Teva (UK) Limited. Teva, however, did not contribute to the design of the study, analysis, and reporting of the results or preparation of the paper.

\section{Authors' Contribution}

Neville Davidson, Ian Keary, and David Houghton contributed to the concept and design of the study. Teresa Camburn extracted and collated the patient record data. Ian Keary analysed the data with input from Neville Davidson and David Houghton. Neville Davidson and Teresa Camburn undertook the clinical interpretation of the results. All authors contributed to the paper.

\section{Acknowledgments}

Strategen Ltd provided analytical and editorial support to the authors, which was funded by Teva (UK) Limited. Teva did not contribute to the design of the study, analysis, and reporting of the results or preparation of the paper.

\section{References}

[1] L. W. Jones, M. J. Haykowsky, J. J. Swartz, P. S. Douglas, and J. R. Mackey, "Early breast cancer therapy and cardiovascular injury," Journal of the American College of Cardiology, vol. 50, no. 15, pp. 1435-1441, 2007.

[2] A. M. Rahman, S. W. Yusuf, and M. S. Ewer, "Anthracyclineinduced cardiotoxicity and the cardiac-sparing effect of liposomal formulation," International Journal of Nanomedicine, vol. 2, pp. 567-583, 2007.

[3] G. Batist, G. Ramakrishnan, C. S. Rao et al., "Reduced cardiotoxicity and preserved antitumor efficacy of liposomeencapsulated doxorubicin and cyclophosphamide compared with conventional doxorubicin and cyclophosphamide in a randomized, multicenter trial of metastatic breast cancer," Journal of Clinical Oncology, vol. 19, no. 5, pp. 1444-1454, 2001.

[4] L. Harris, G. Batist, R. Belt et al., "Liposome-encapsulated doxorubicin compared with conventional doxorubicin in a randomized multicenter trial as first-line therapy of metastatic breast carcinoma," Cancer, vol. 94, no. 1, pp. 25-36, 2002.

[5] S. Chan, N. Davidson, E. Juozaityte et al., "Phase III trial of liposomal doxorubicin and cyclophosphamide compared with epirubicin and cyclophosphamide as first-line therapy for metastatic breast cancer," Annals of Oncology, vol. 15, no. 10, pp. 1527-1534, 2004.

[6] G. Batist, L. Harris, N. Azarnia, L. W. Lee, and P. Daza-Ramirez, "Improved anti-tumor response rate with decreased cardiotoxicity of non-pegylated liposomal doxorubicin compared with conventional doxorubicin in first-line treatment of metastatic breast cancer in patients who had received prior adjuvant doxorubicin: results of a retrospective analysis," Anti-Cancer Drugs, vol. 17, no. 5, pp. 587-595, 2006.

[7] Myocet [UK Prescribing Information], Cephalon, Welwyn Garden City, UK, 2011, http://www.medicines.org.uk/.
[8] P. Schmid, J. Krocker, C. Jehn et al., "Primary chemotherapy with gemcitabine as prolonged infusion, non-pegylated liposomal doxorubicin and docetaxel in patients with early breast cancer: final results of a phase II trial," Annals of Oncology, vol. 16, no. 10, pp. 1624-1631, 2005.

[9] A. Antón, A. Ruiz-Simon, A. Plazaola et al., "Phase II study of a 3-weekly liposome-encapsulated doxorubicin/docetaxel/ pegfligrastrim in combination with weekly trastuzumab as primary treatment in Her2 positive (Her2+) early stage breast cancer patients (II-IIIa). GEICAM 2003-03 Study," Cancer Research, vol. 69, supplement 2, p. 511, 2009.

[10] British Society of Echocardiography Education Committee, "Echocardiography: Guidelines for Chamber Quantification," http://www.bhf.org.uk/publications/view-publication.aspx?ps= 1001601.

[11] "Defining research. National Research Ethics Service. Ref: 0987," December 2009, http://www.nres.nhs.uk/applications/isyour-project-research/.

[12] A. Seidman, C. Hudis, M. Kathryn Pierri et al., "Cardiac dysfunction in the trastuzumab clinical trials experience," Journal of Clinical Oncology, vol. 20, no. 5, pp. 1215-1221, 2002.

[13] D. J. Slamon, B. Leyland-Jones, S. Shak et al., "Use of chemotherapy plus a monoclonal antibody against her2 for metastatic breast cancer that overexpresses HER2," The New England Journal of Medicine, vol. 344, no. 11, pp. 783-792, 2001.

[14] Clinicaltrials.gov, "Combination therapy with Myocet (doxorubicin $\mathrm{HCl}$ liposome for injection) in patients with HER2positive breast cancer," http://www.clinicaltrials.gov/ct2/show/ NCT000712881.

[15] J. Cortes, S. DiCosimo, M. A. Climent et al., "Nonpegylated liposomal doxorubicin (TLC-D99), Paclitaxel, and Trastuzumab in HER-2-overexpressing breast cancer: a multicenter phase 1/ll study," Clinical Cancer Research, vol. 15, no. 1, pp. 307-314, 2009.

[16] M. Venturini, C. Bighin, F. Puglisi et al., "A multicentre phase II study of non-pegylated liposomal doxorubicin in combination with trastuzumab and docetaxel as first-line therapy in metastatic breast cancer," Breast, vol. 19, no. 5, pp. 333-338, 2010. 


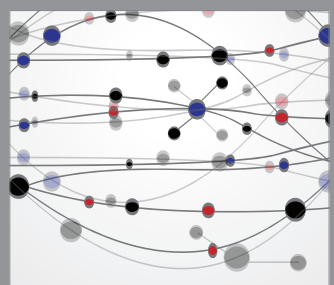

The Scientific World Journal
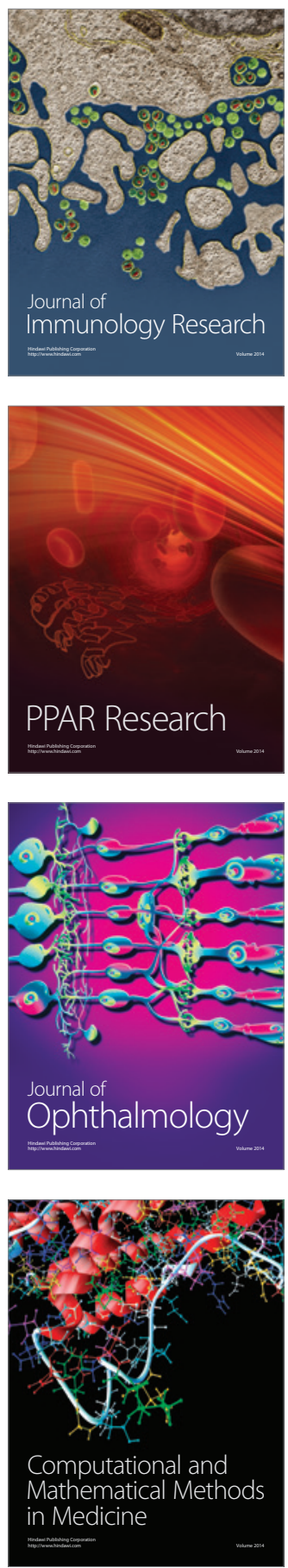

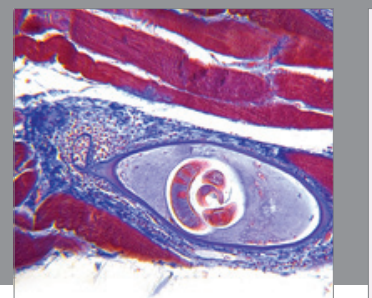

Gastroenterology

Research and Practice
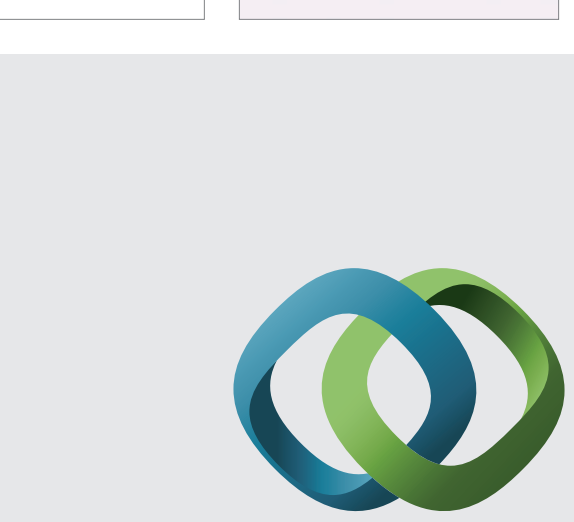

\section{Hindawi}

Submit your manuscripts at

http://www.hindawi.com
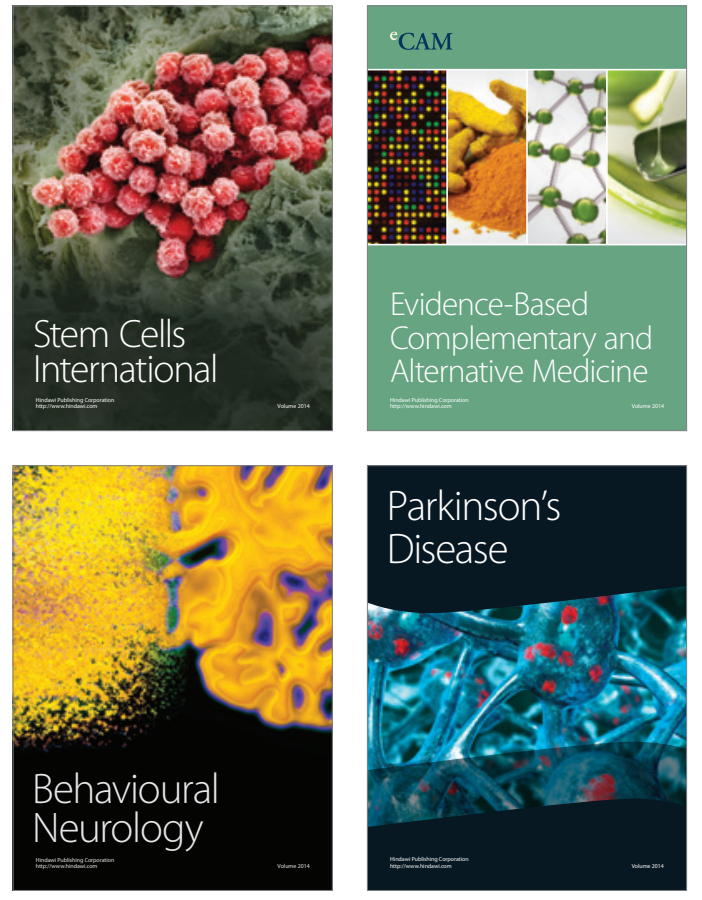
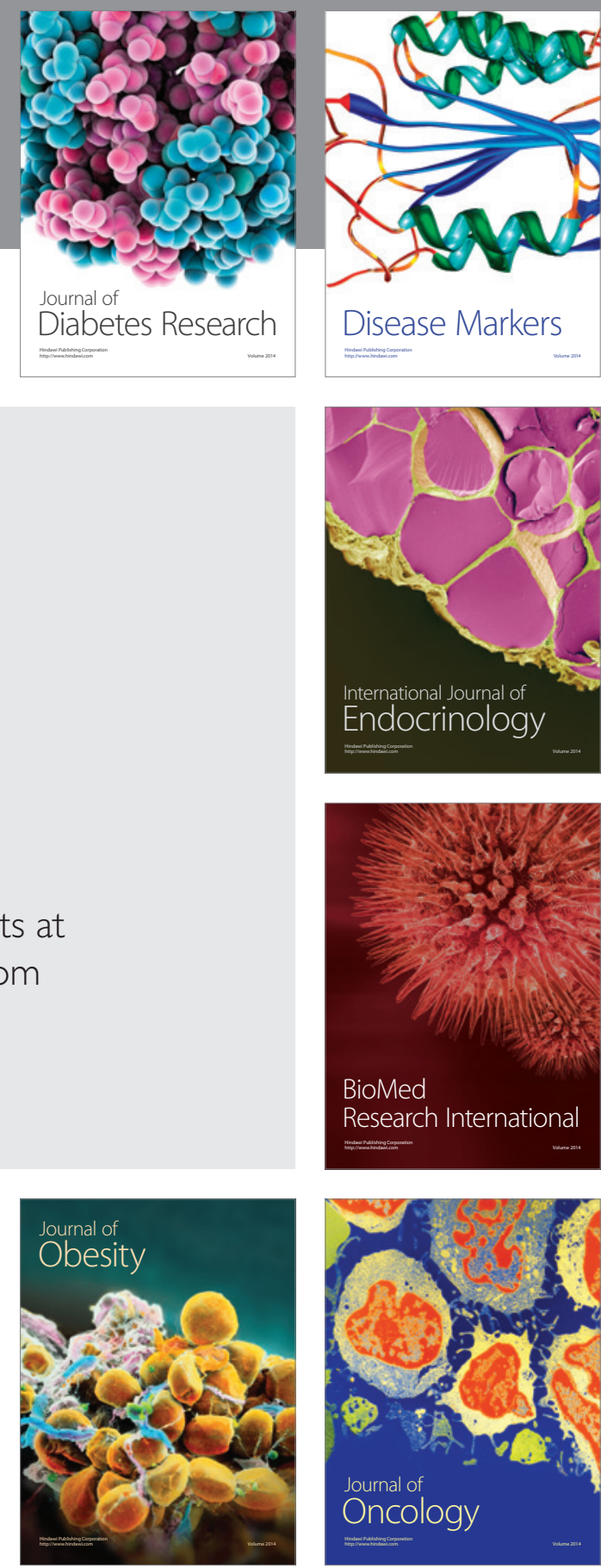

Disease Markers
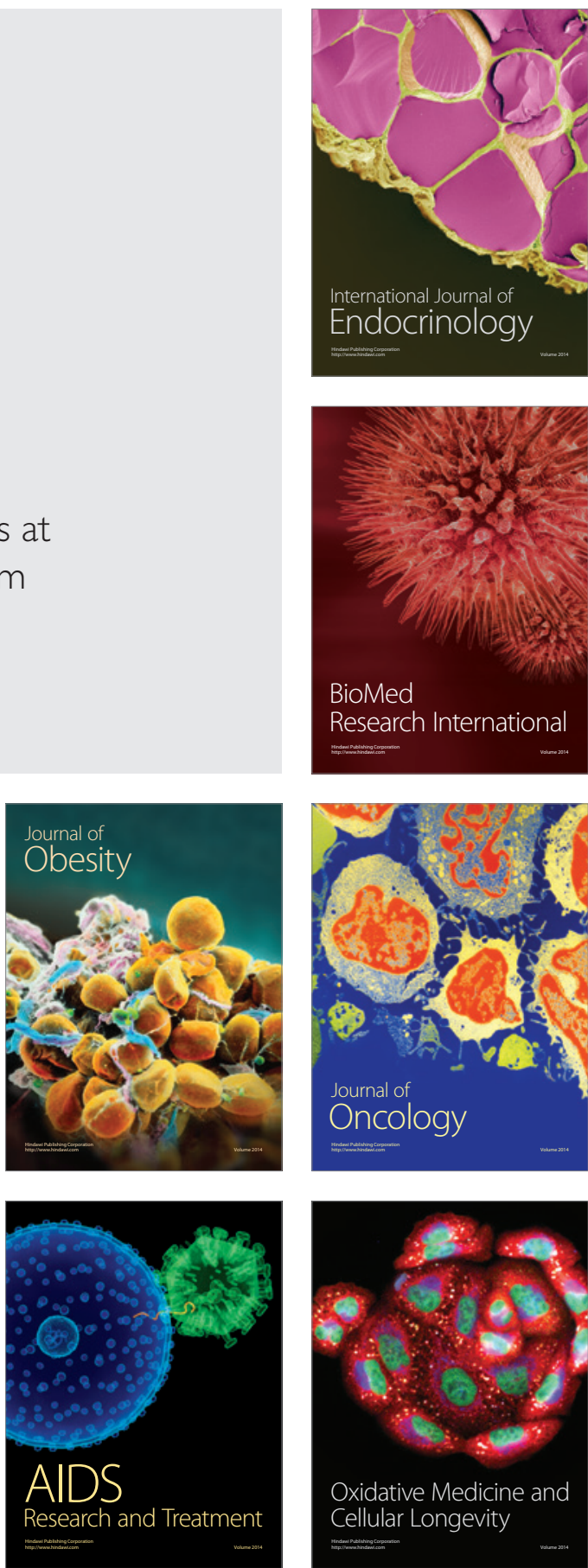